\title{
Sub-Criticality Measurement with Source Term for Research Reactor in Inverse Kinetics Method
}

\author{
N. Jahan', M. M. Rahman', M. Q. Huda' ${ }^{2}$, S. M. Seo ${ }^{3}$ \\ ${ }^{1}$ Institute of Energy Science, Atomic Energy Research Establishment, Savar, Bangladesh \\ ${ }^{2}$ Quality Management Division, Bangladesh Atomic Energy Commission, Dhaka, Bangladesh \\ ${ }^{3}$ Research Reactor Design and Engineering Division, Korea Atomic Energy Research Institute, Daejeon, Republic of Korea \\ Email: shilas_door@yahoo.com
}

How to cite this paper: Jahan, N., Rahman, M.M., Huda, M.Q. and Seo, S.M. (2017) Sub-Criticality Measurement with Source Term for Research Reactor in Inverse Kinetics Method. World Journal of Nuclear Science and Technology, 7, 129. 135 .

https://doi.org/10.4236/wjnst.2017.73011

Received: April 4, 2017

Accepted: June 12, 2017

Published: June 15, 2017

Copyright $\odot 2017$ by authors and Scientific Research Publishing Inc. This work is licensed under the Creative Commons Attribution International License (CC BY 4.0).

http://creativecommons.org/licenses/by/4.0/

\begin{abstract}
In reactor physics tests, it is important to monitor sub-criticality continuously during criticality approach. Reactivity measurements by the inverse kinetics method are widely used during the operation of a nuclear reactor. This technique is successfully applied at sufficiently high power level or to a core without an external neutron source where the neutron source term in point reactor kinetics equations may be neglected. For operation at low power levels or in the sub-critical domain, the increase in the fluctuation of the neutron signal may cause difficulties in the evaluation of reactivity and the effect of direct emission from the external neutron source may not be neglected. Therefore, contribution of the neutron source must be taken into account and this implies knowledge of a quantity proportional to the source strength, which calls the source term and then it should be determined. The research work has been conducted to measure reactivity with source term using a dedicated reactivity measurement system by the Least Square Inverse Kinetics Method (LSIKM). Application to a simulator of HANARO research reactor, Korea Atomic Energy Research Institute (KAERI), with known source strength and reactivity worth has showed consistent and satisfactory agreement.
\end{abstract}

\section{Keywords}

Source Strength, Sub-Critical, Reactivity, Reactor Kinetics, Inverse Kinetics Method

\section{Introduction}

The inverse kinetics (IK) is widely used for reactivity measurement during nuclear reactor operation. The IK method is a reactivity measurement based on the 
point reactor kinetics equations. The IK equation involves the neutron source term, and then determination of the neutron source strength is required. Since reactor is been operated in a steady-state condition, the reactivity can be determined using the point kinetics equations and the source term can be neglected in this case. However, for operation at low power, [1] [2] for instance at start-up, the contribution of the neutron source must be explicitly taken into account. Therefore, for operation at low power levels, the contribution of external source term must be taken into account to get accurate reactivity calculation.

It was seen that the source term is not so easy to be determined and so the procedure is still under determined. In general, the first step is to construct the program which is able to calculate the reactivity neglecting source term using the signal from reactor core. For this purpose a dedicated on-line reactivity measurement system has been developed that can acquire instantaneous neutron flux signal from reactor instrumentation channel and calculate reactivity. Using this reactivity without source and the signal value, the external source term is to be determined by least square inverse kinetic method. After determining source term, its value has been added to the algorithm and the reactivity has been calculated again with developed reactivity meter, considering the source term. The new measured value of the reactivity is more precise than the measurement which neglects source term [3] [4]. A simulation of the rod drop experiment that was done in Research Reactor Design and Engineering division, Korea Atomic Energy Research Institute, where the reactor was modelled and simulated, had the objective to determine the numerical value for the source term and reactivity. The value of the reactivity determined by the reactivity meter for HANARO research reactor has discussed in the related section.

\section{Inverse Kinetics with Source Term}

The point kinetic equations describe the kinetic behavior of the reactor. That means these equations describe the change in the neutron density within the reactor due to a change in reactivity and are the most fundamental [5] relations. The standard point kinetics equations can be written as:

$$
\frac{\mathrm{d} n}{\mathrm{~d} t}=\frac{\rho\left(t_{j}\right)-\beta}{\Lambda} n\left(t_{j}\right)+\sum_{i=1}^{6} \lambda_{i} C_{i}\left(t_{i}\right)+S
$$

And

$$
\frac{\mathrm{d} C_{i}}{\mathrm{~d} t}=-\lambda_{i} C_{i}\left(t_{j}\right)+\frac{\beta_{i}}{\Lambda} n\left(t_{j}\right)
$$

where $n\left(t_{j}\right)$ is the total number of neutrons in the core, which is directly proportional to the reactor power at time $t_{p} C_{i}\left(t_{j}\right)$ is the total number of precursors of delayed neutrons of group $i . S$ is the total neutron source strength supposed to be constant in time, $\Lambda$ is the prompt neutron generation time and $\rho$ the reactivity to be determined. The constants $\beta_{i}$ and $\lambda_{i}$ are the fraction and decay constant of delayed neutron precursor of group $i$, respectively, and $\beta_{\text {eff }}=\sum_{i=1}^{6} \beta_{i}$ is the effective delayed neutron fraction. 
In practice, for discrete time series data, assuming that the reactor power change for the time interval $\Delta t$ is given by $n\left(t_{j}\right)=n_{0}+\frac{n\left(t_{j}\right)-n\left(t_{j-1}\right)}{\Delta t} t_{j}$

The inverse kinetics equation can be written as:

$$
\rho\left(t_{j}\right)=\frac{\Lambda}{n\left(t_{j}\right)} \frac{\mathrm{d} n}{\mathrm{~d} t}+\beta-\frac{\Lambda}{n\left(t_{j}\right)} \sum_{i=1}^{6} \lambda_{i} C_{i}\left(t_{j}\right)-\frac{\Lambda}{n\left(t_{j}\right)} S
$$

where

$$
C_{i}\left(t_{i}\right)=C_{i}(0) \exp \left(-\lambda_{i} t_{i}\right)+\frac{B_{i}}{\Lambda} \exp \left(-\lambda_{i} t_{i}\right) \int_{0}^{t_{j}} n\left(t^{\prime}\right) \exp \left(\lambda_{i} t^{\prime}\right) \mathrm{d} t^{\prime}
$$

Equation (3) is suitable for on-line digital reactivity meter provided that the quantity $\Lambda \mathrm{S}$ is known. This term is called source term and its dimension is the same as that of the measured quantity $n\left(t_{j}\right)$. In general, $n\left(t_{j}\right)$ is not measured directly, but a quantity proportional to $n\left(t_{j}\right)$. The measured quantity will be denoted by $P(t)$ which is equal to $c n(t)$, with $c$ a proportionality constant. Although the notation $P$ suggests that the reactor power is measured, $P$ can in fact be any quantity proportional to the number of neutrons in the reactor [6]. For reactor operating at sufficiently high power the effect of the source term on the calculated reactivity can be neglected. However, at a lower power the source term should be considered, because otherwise zero reactivity will be obtained for a subcritical reactor at constant power.

\section{Rod Drop Experiment with Reactor Simulator}

The method for determining reactivity with source term has been tested with the reactor core simulator of Research Reactor Design and Engineering Division, KAERI based on Least Squares Inverse Kinetics Method (LSIKM). According to this method first the reactivity without the source term was determined implementing an indigenous on-line reactivity meter. Let all terms except the source term on the right side of Equation (3) be $\rho^{\prime}\left(t_{j}\right)$ for simplicity. Then Equation (3) is rewritten as Equation (4). Let $\rho^{\prime}\left(t_{j}\right)$ denote a reactivity without source hereafter:

$$
\rho\left(t_{j}\right)=\rho^{\prime}\left(t_{j}\right)-\frac{\Lambda}{n\left(t_{j}\right)} S
$$

The two unknown constants, $\rho\left(t_{j}\right)$ and $S$, in Equation (4) can be solved when the time series data, $n\left(t_{j}\right)$ are provided and $\rho^{\prime}\left(t_{j}\right)$ calculated by the digital reactivity meter. To apply the least squares approximation, Equation (4) is rearranged as given as given in Equation as a fitting model:

$$
\rho^{\prime}\left(t_{j}\right)=\rho\left(t_{j}\right)+\frac{\Lambda}{n\left(t_{j}\right)} S
$$

Following simulation conditions of rod drop experiment has been used to demonstrate the evaluation of reactivity and source strength:

Initial power: $0.1 \% \mathrm{FP}$ 
Source strength: $2.6 \% \mathrm{FP} / \mathrm{s}$

Initial reactivity: $-1.0 \times 10^{-3} \$$

Scram reactivity worth: $-4.0 \times 10^{3} \$$

For this power transient data, first the reactivity without source, $\rho^{\prime}\left(t_{j}\right)$ is calculated using the constants of delayed neutron precursors as given in Table 1 and the neutron generation time, $\Lambda$, of 0.000039 . Then with the data of $\rho^{\prime}\left(t_{j}\right)$ and $n\left(t_{j}\right), \rho\left(t_{j}\right)$ and $S$ are measured with four different fitting models as listed in Table 2, to find out the best fitting model. The variables of each model are plotted in Figure 1. The non-fluctuating values should fall on the 45 degree line crossing these points on respective ordinate. For model-1 the fitted line is of negative slope, resulting in negative value of neutron source strength. Although the same variables are used in model- 2 and model-3, the results are different. This is because variables are used in different axis. Only the fitted line of model4 falls on the 45 degree line. As a consequence only model 4 provided the closest agreement with simulation result.

With this fitting model the value of reactivity with source and the external source were obtained as $-4.0 \times 10^{3} \$$ and $2.6 \% \mathrm{FP} / \mathrm{s}$ respectively and match the given condition. Once source is obtained, substituting $S$ in Equation (3), the reactivity, $\rho\left(t_{j}\right)$, is re-calculated for all the data and is plotted as "with source". Reactivity now is a constant value, depending only upon the fluctuation of the signal [7] [8], but not giving zero reactivity. Figures 2(a)-(c) shows the signal versus time, reactivity without source and reactivity with source curve respectively.

Table 1. Constants of delayed neutron precursors.

\begin{tabular}{ccc}
\hline Group $\boldsymbol{i}$ & $\boldsymbol{\lambda}$ & $\boldsymbol{\beta}$ \\
\hline 1 & 0.0124 & 0.033 \\
2 & 0.0305 & 0.219 \\
3 & 0.111 & 0.196 \\
4 & 0.301 & 0.395 \\
5 & 1.14 & 0.115 \\
6 & 3.01 & 0.042 \\
\hline
\end{tabular}

Table 2. Fitting models.

\begin{tabular}{cc}
\hline Model & Fitting Model \\
\hline 1 & $n\left(t_{j}\right)=\frac{1}{\rho\left(t_{j}\right)} \rho^{\prime}\left(t_{j}\right) n\left(t_{j}\right)-\frac{\Lambda \mathrm{S}}{\rho\left(t_{j}\right)}$ \\
2 & $\frac{1}{n\left(t_{j}\right)}=\frac{1}{\Lambda \mathrm{S}} \rho^{\prime}\left(t_{j}\right)-\frac{\rho\left(t_{j}\right)}{\Lambda \mathrm{S}}$ \\
$\rho^{\prime}\left(t_{j}\right)=\Lambda \mathrm{S} \frac{1}{n\left(t_{j}\right)}+\rho\left(t_{j}\right)$ \\
4
\end{tabular}




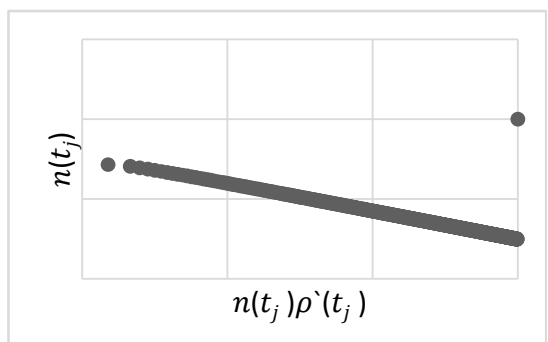

Model-1

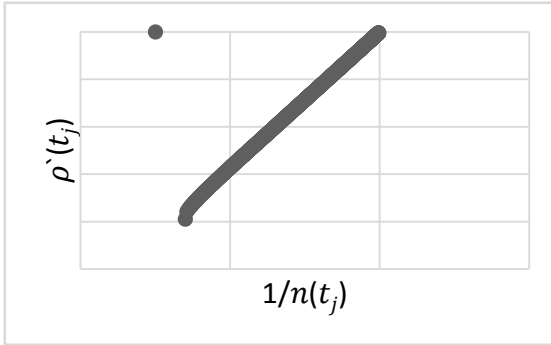

Model-3

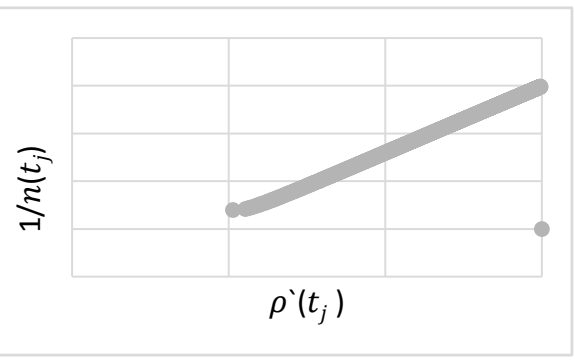

Model-2

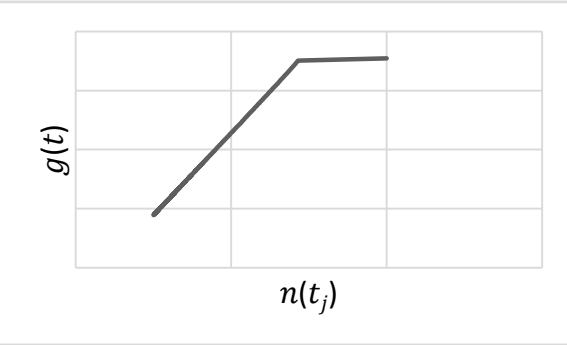

Model-4

Figure 1. X-Y coordinate plot of variables and fitting line.

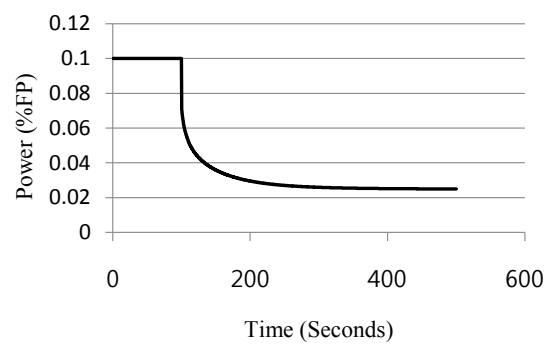

(a)

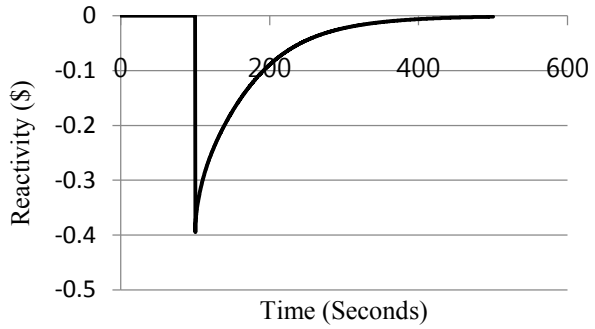

(b)

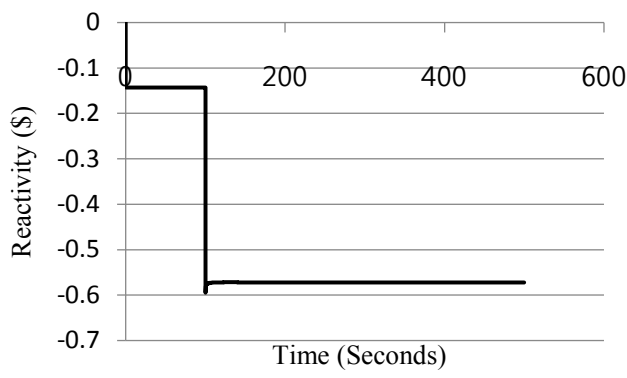

(c)

Figure 2. (a) Signal versus time; (b) Reactivity without source; (c) Reactivity with source.

\section{Result and Discussion}

The precision of measured reactivity from reactivity meter has been validated from the differential rod worth curve. Figure 3 provides the differential rod worth curve of HANARO research reactor. From the differential curve, reactivity worth at $75 \mathrm{~mm}$ rod position is $.019767 \$$. And the experimental data of reactivity worth from HANARO research reactor on the same position is about $0.0045 \$$ which is one forth of that from differential curve. Similarly experimental reactivity value at $275 \mathrm{~mm}$ control rod position is about $0.011 \$$ and from 


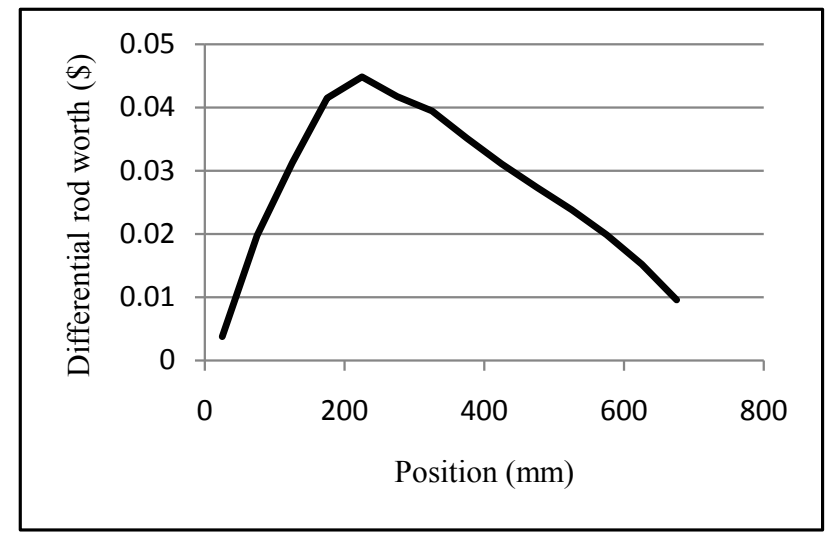

Figure 3. Differential rod worth $(\$)$ versus position $(\mathrm{mm})$ curve.

differential curve it is $0.0414 \$$ which is about four times higher than experimental value. As the differential curve considers the effect of four control rods whereas reactivity meter produces calculation considering the impact of only one control rod, obviously, the reactivity worth from reactivity meter is four times less than the value from graph. Therefore, it is proved that experimental data has good agreement with differential curve which consequently indicates that the develop reactivity meter can measure reactivity with source accurately.

\section{Conclusions}

The reactivity measurement with source term by least square inverse kinetics method for sub-critical domain has been studied. For low levels of neutron signal, the degree of fluctuation of the signal increases and will cause difficulties in the evaluation of the source strength as well as reactivity. The drawback of this method is that the regression would be based on the two variables $x(t)$ and $y(t)$ which both may contain considerable noise. However, it may be concluded that the Least-Squares method is well suited to estimate the reactivity with source term of a research reactor, especially when strong noise is present in the measured reactor power signal, which will normally be the case at low power.

\section{References}

[1] Tamura, S. (2003) Signal Fluctuation and Neutron Source in Inverse Kinetics Method for Reactivity Measurement in the Sub-Critical Domain. Journal of Nuclear Science and Technology, 40, 153-157. https://doi.org/10.1080/18811248.2003.9715345

[2] Hoogenboom, J.E. and Van der Sluijs, A.R. (1988) Neutron Source Determination for On-Line Reactivity Measurement. Annals of Nuclear Energy, 15, 553-559. https://doi.org/10.1016/0306-4549(88)90059-X

[3] Takeuchi, M., Yamashita, K., Tamura, S., et al. (1996) Sub-Criticality Estimation by Inverse Kinetics. Preprints, 1996 Fall Meeting, Atomic Energy Society of Japan, Sendai, A23.

[4] Itagaki, M. and Kitano, A. (1999) Revised Source Strength Estimation for Inverse Neutron Kinetics. Preprints, 1999 Fall Meeting, Atomic Energy Society of Japan, Hiroshima, G20. 
[5] Keepin, G.R. (1965) Physics of Nuclear Kinetics. Addison-Wesley, New York.

[6] Lamash, J.R. (1966) Introduction to Nuclear Theory. Addison-Wesley, Massachusetts.

[7] Tamura, S. (2002) Reactivity Analysis by Inverse Kinetics Method-Effect of External Neutron Source. Preprints, 2002 Annual. Meeting, Atomic Energy Society of Japan, Koube, G58.

[8] Wakabayashi, G., Yonemura, Y., Heguri, H., Matoba, M., Hashimoto, K. and Horiguchi, T. (2001) Measurement of Varying Sub-Critical Reactivity with Digital TimeSeries Data Acquisition System Using Difference Filter Technique. IEEE Nuclear Science Symposium Conference Record, 1, 403-405.

Submit or recommend next manuscript to SCIRP and we will provide best service for you:

Accepting pre-submission inquiries through Email, Facebook, LinkedIn, Twitter, etc. A wide selection of journals (inclusive of 9 subjects, more than 200 journals)

Providing 24-hour high-quality service

User-friendly online submission system

Fair and swift peer-review system

Efficient typesetting and proofreading procedure

Display of the result of downloads and visits, as well as the number of cited articles Maximum dissemination of your research work

Submit your manuscript at: http://papersubmission.scirp.org/

Or contactwjnst@scirp.org 